

\section{EXPEDIENTE}

Universidade do Estado do Rio de Janeiro - UERJ

Instituto de Estudos Sociais e Políticos - IESP

CADERNOS DE ESTUdOS SOCIAIS E POLÍTICOS www.e-publicacoes.uerj.br/index.php/CESP

\section{COMITÉ EDITORIAL}

Anna Carolina Venturini, IESP-UERJ

Felipe Munhoz de Albuquerque, IESP-UERJ

Leonardo Nóbrega da Silva, IESP-UERJ

Marcelo Borel, IESP-UERJ

Marcia Rangel Candido, IESP-UERJ

Marina Rute Pacheco, IESP-UERJ

Mariane Silva Reghim, IESP-UERJ

Natália Leão, IESP-UERJ

Paulo Joaquim Da Silva Rodrigues, IESP-UERJ

Raul Nunes de Oliveira, IESP-UERJ

\section{CAPA, LAYOUT E DIAGRAMAÇÃO}

Marcia Rangel Candido

Raul Nunes de Oliveira 


\section{Apresentação}

Mariane Silva Reghim

\section{Dossiê}

É Possível Fazer Ciências Sociais sem uma Análise Crítica das

Categorias de Diferenciação? Uma Proposição Feminista

Natália Corazza Padovani

As Perspectivas Teóricas Queer e o Uso Cotidiano da Língua

Portuguesa

Helza Ricarte Lanz e Juliane Noack Napoles

Raça e Violência Sexual: Âmbito de Aplicação da Vitimodogmática?

Amanda Bessoni Boudoux Salgado e José Roberto Macri Jr.

What Happened with "What Happened, Miss Simone?"? - Assistindo ao Documentário Pela Ótica do Feminismo Negro

Rafael Pinto Ferreira de Queiroz

O Racismo Institucional no Brasil: Contribuições de Louis Althusser para o Debate

\section{Artigos}

O Voto Econômico na América Latina entre 2004 - 2012: Avaliação da Economia e do Desempenho do Governo em Políticas Públicas e de Combate à Corrupção

Flávia Bozza Martins

Eleições Presidenciais de 2014: Reflexões sobre o Capital Político e a

Capitalização de Votos de Marina Silva

Bruno Fonseca Gurão e Mirna Tonus

\section{Resenha}

Neoliberalismo Desde Baixo, Pós-Fordismo Periférico e Cálculos Emancipatórios

Igor Peres

Sobre Autogestão nas Fábricas Recuperadas no Brasil: (R)Existindo no Mercado 


\title{
O Voto Econômico na América Latina entre 2004 - 2012: Avaliação da Economia e do Desempenho do Governo em Políticas Públicas e de Combate à Corrupção
}

\author{
The Economic Vote in Latin America between 2004 - 2012: Evaluating Economics and Government \\ Performance in Public Policies and Combating Corruption
}

Flávia Bozza Martins ${ }^{1}$

\begin{abstract}
RESUMO
O objetivo deste trabalho é verificar o que pesou na avaliação positiva do presidente latino-americano entre 2004 e 2012. Buscou-se investigar se a avaliação dos incumbentes esteve influenciada pelo desempenho econômico e atuação dos governos sobre políticas públicas e de combate à corrupção. Nossa hipótese é operacionalizada pelas variáveis da literatura do voto econômico e incorpora, além da variável ideologia, variáveis que medem o desempenho dos presidentes em políticas públicas e de combate à corrupção. Para tanto, elaboramos banco de dados agregados e foram analisadas 36 eleições, referentes a dezoito países latino-americanos. Os resultados relativos à percepção do desempenho do mandatário têm impacto sobre a avaliação positiva do mesmo. Já os dados objetivos de crescimento econômico e índice de corrupção não impactam diretamente a avaliação do presidente. Contudo, se mostram capazes de explicar a percepção do desempenho do presidente por parte dos eleitores, indicando impacto indireto sobre a avaliação positiva do presidente.
\end{abstract}

PALAVRAS-CHAVE: voto econômico; comportamento eleitoral da América Latina; percepção do desempenho do incumbente.

\begin{abstract}
The objective of this work is to verify what aspects were important on the positive evaluation of Latin American president between 2004 and 2012. We aimed to investigate if the positive evaluation on the incumbents were influenced by the economic performance and the president's performance on public policies and anti-corruption. Our hypothesis uses the variables indicated by the economic voting literature - objective data and subjective evaluation of economy - and incorporates, besides de ideology variable, other variables that measure the president's performance in subjects that are not economical (objective and subjective data). We analyzed thirty six elections, referring to eighteen Latin American countries, with aggregate data. The Hierarchical Regression demonstrated that the data related to the perception of the president's performance have impact on his approval. The objective data of GPD growth and social investment did not impact directly on the president's evaluation. However, they are able to explain the variables of voters' perception of the president's performance, indicating indirect impact on the positive president's evaluation, since they contribute for the formation of subjective preferences on votes.
\end{abstract}

KEY-WORDS: Economic Voting; electoral behavior in Latin America, perception of the incumbent's performance.

1 Doutora em Ciência Política pelo IESP/UERJ. Mestra em Ciência Política pela UFPR. Pesquisadora na área de opinião pública e comunicação política. 


\section{INTRODUÇÃO: O VOTO ECONÔMICO NA AMÉRICA LATINA}

O voto econômico é a teoria mais utilizada pelos pesquisadores da área para explicar o comportamento eleitoral nas últimas décadas ${ }^{2}$. O pressuposto básico desta teoria é bastante simples: o eleitor identifica melhoria na sua situação econômica ou na do país, atribui a responsabilidade ao presidente, e o premia com o seu voto. Em caso contrário, a identifica piora da situação economia e o pune, votando no candidato da oposição.

Apesar de ter sido deveras explorado em países com democracias mais antigas e, por isso dotadas de instituições possivelmente mais estáveis, os estudos sobre o voto econômico ainda fazem parte de uma agenda incipiente no que se refere à abordagem ao conjunto de países que vai além da Europa Ocidental e Estados Unidos (Remmer, 1991; Weyland, 1998; Lewis-Beck e Stegmaier, 2008; Lewis-Beck e Ratto, 2013; Singer, 2013). De modo geral, quando se fala em carência de estudos sobre comportamento eleitoral para além de países de economias prósperas e tidas como estáveis, está se falando em estudo de democracias que vão além da Europa Ocidental e Estados Unidos.

Os estudos sobre o voto econômico na América Latina, mesmo os estudos de caso, ainda fazem parte de uma agenda em desenvolvimento. Lewis-Beck e Stegmaier (2008) apontam que países como Peru, México e Argentina detêm o maior número de casos de investigação e publicação na língua inglesa. No Brasil, Carreirão (1998), Rennó e Peixoto (2011), Veiga e DuttRoss (2016) produziram pesquisas sobre a relação entre economia e voto nas eleições presidenciais brasileiras. E apesar da existência da temática focada em estudos de caso em outros países latino-americanos, ainda são necessárias novas análises de amostra transnacionais que englobam o tema em diversos países dessa região. A questão que perdura baseia-se no fato de averiguar se em meio a uma democracia jovem - e portanto mais frágil -, crises econômicas, e pobreza, há espaço para a economia impactar o comportamento eleitoral. Seria essa a maior demanda dos eleitores inseridos em tais contextos? Haveria o mesmo comportamento racional que aquele existente nos países de economias prósperas? Ou seriam outras as prioridades e as competências? O objetivo deste artigo é gerar respostas a tais questionamentos da literatura

2 Para mais explicações das razões pelas quais a teoria do voto econômico é a mais utilizada, em detrimento das correntes sociológica e psicológica do comportamento eleitoral, ver Dalton e Klingeman (2009). 
internacional, identificando o que impacta na avaliação positiva do presidente latino-americano sob a luz da teoria do voto econômico.

O voto econômico neste trabalho é compreendido de uma forma mais ampla, implicando a avaliação retrospectiva de outros elementos entregados pelo governo em termos de políticas públicas e de combate à corrupção, além da economia. Dessa forma, além de responder à literatura internacional sobre a existência ou não do voto econômico no país, pretendemos contribuir demonstrando que a incorporação de demandas específicas da região nos estudos de comportamento eleitoral na América Latina auxiliará na melhor compreensão da formação de preferências dos eleitores. Com isso, buscamos investigar se e em que medida a avaliação do desempenho do presidente sobre a economia e políticas em áreas importantes para a agenda política da América Latina possui efeito sobre a avaliação positiva do mandatário (condição necessária para o voto de acordo com Lewis-Beck e Stegmaier, 2008; Weyland, 1998, Camargos, 2006).

Calcados nos argumentos apontados pelos estudiosos da área que defendem a necessidade de estudos acerca do comportamento eleitoral dentro de democracias transicionais, isto é, dentro de democracias em processo de estabilização, elegemos a América Latina como uma região de interesse de estudo, devido ao seu contexto de diversos países dividirem um cenário de instituições democráticas recentes, cenários de instabilidade econômica e, com isso, demandas que podem vir a ser similares.

Em razão dessas demandas, nosso argumento é de que a racionalidade do eleitor latinoamericano encontraria sentido não somente pautado na avaliação da situação econômica, como também na avaliação da atuação do presidente em outros tópicos relevantes para a agenda política da região, verificadas por variáveis que mensuram a avaliação da atuação do presidente sobre políticas públicas e de combate à corrupção. Assim, argumentamos que, ao responderem à avaliação da economia e do desempenho do presidente sobre tais políticas, os eleitores demonstrariam um comportamento eleitoral que pode ser comparado ao daqueles de eleitores que possuem maior tempo de experiência democrática. Essa expectativa reside também no fato de a redemocratização já fazer parte de um passado mais distante, e os eleitores já terem acumulado cerca de 30 anos de experiência no ato de votar.

A avaliação positiva do presidente será utilizada como variável dependente por ser considerada uma proxy do voto por razões teóricas e metodológicas que serão explicadas mais adiante (Lewis-Beck e Stegmaier, 2008; Weyland, 1998 e 2000; Camargos, 2006). A hipótese é de 
que o reconhecimento de resultados positivos sobre a economia e desempenho do presidente sobre políticas públicas e de combate à corrupção (dados subjetivos) impactem a avaliação positiva do presidente. Além disso, também se espera que os dados objetivos sobre economia, investimento social e índice de percepção da corrupção contribuam para a avaliação positiva do presidente. Todas essas variáveis - provenientes de surveys e dados

agregados - estão associadas às principais preocupações do eleitor latino-americano segundo o survey Latinobarômetro, que devem produzir efeito sobre a formação de preferências do eleitorado. A ideologia é inserida como variável de controle.

A estratégia empírica foi realizar análise fatorial a fim de reduzir o número de variáveis e associar aquelas mais semelhantes entre si. O resultado da análise fatorial gerou três fatores que dizem respeito a: i) variáveis de avaliação do desempenho sobre economia e políticas públicas e de combate à corrupção (variáveis endógenas), ii) dados objetivos da economia, investimento social e índice de percepção da corrupção, e iii) ideologia (sendo os dois últimos variáveis exógenas). Uma vez realizada a análise fatorial, adotamos a análise de regressão em passos, também conhecida como modelo hierárquico, com o intuito de verificar o impacto de cada um dos fatores sobre a variável dependente de maneira desvinculada.

Os resultados indicam que o voto econômico ocorre na América Latina e que a percepção sobre políticas públicas e de combate à corrupção também explicam a avaliação positiva do presidente. Os dados objetivos não impactam diretamente a avaliação positiva do presidente, mas produzem efeito sobre a formação da percepção do eleitor latino-americano quanto à percepção da economia e percepção do desempenho do presidente em políticas públicas e de combate à corrupção.

O artigo será organizado da seguinte forma: na primeira sessão serão apresentadas as contribuições mais recentes da literatura no que se refere a estudos transnacionais na América Latina; na seção seguinte serão apresentadas as hipóteses, seguidas das variáveis utilizadas; posteriormente, serão apresentadas as análises para, por fim, serem tecidas algumas considerações finais acerca desse estudo e sua contribuição para essa área de estudos. 


\section{OS ESTUDOS TRANSNACIONAIS}

Remmer (1991), que apresenta certo pioneirismo ao traçar "The Political Impact of Economic Crisis in Latin America in the 80's", busca responder às perguntas: qual o impacto da crise econômica na política de democracias não desenvolvidas? E, ainda: qual o efeito do voto econômico em tais democracias? Em um estudo abrangendo o recorte de 1982 a 1990³ a partir de dados agregados, a autora analisa 21 eleições $(\mathrm{N}=21)$.

Utiliza três variáveis dependentes: perdas do incumbente (representado pelo percentual de quanto o mandatário perdeu entre uma eleição e outra anterior); voto no incumbente (percentual de votos recebidos) e quantidade de votos recebidos (aqui se considera no cálculo a dispersão dos votos dos concorrentes, que não está contemplada nas variáveis anteriores). Como variáveis independentes estão: taxa de inflação; crescimento econômico; variação da inflação e variação do crescimento econômico. Os modelos baseados nessas variáveis independentes se mostraram estatisticamente significativos, e contribuíram com 60\% na variação da perda dos votos no incumbente, $74 \%$ na variação de voto no incumbente e $67 \%$ na variação dos votos totais. Nesse contexto, foi a inflação o fator econômico mais impactante. O que, para Singer (2013), é fortemente explicável pelo contexto de altíssimos índices de inflação vivenciado na América Latina nesse período, o que viria a gerar forte preocupação no eleitor.

Veiga (2012), em seu trabalho "Economic Voting in an Age of Grothw and Poverty Reduction: Electoral Response in Latin America", busca verificar o impacto da economia sobre o voto no incumbente. Para tanto, a autora lança mão de dados subjetivos e objetivos (em nível agregado). Sua análise engloba eleições latino-americanas entre o período de 1995 a 2010. Compuseram sua pesquisa 58 eleições para o Executivo e Legislativo $(\mathrm{N}=58)$. Os dados subjetivos foram retirados do Latinobarômetro.

O modelo de regressão hierárquica proposto pela autora contempla dois passos de impacto das variáveis. 1) Variáveis exógenas (representadas no modelo de Veiga pelos dados objetivos da economia - crescimento do PIB, investimento social e inflação) seriam as variáveis independentes. Estas, por seu turno, viriam a impactar as 2) variáveis endógenas do modelo,

3 Como a autora registra, a América Latina concentrou nesse intervalo de tempo o mais alto número de eleições do que em qualquer outro período anterior. 
quais sejam, as variáveis intervenientes, a avaliação subjetiva da economia (avaliação econômica prospectiva sociotrópica e avaliação econômica retrospectiva sociotrópica). Ambos os conjuntos de variáveis do modelo - exógenas e endógenas - se mostraram significativas ao explicar a variável dependente voto no incumbente.

Os achados de Veiga demonstram que, quando o modelo contou apenas com os dados macroeconômicos, esses dados não impactaram o voto no incumbente. O investimento social, entretanto, mostrou ser significativo ao impactar a variável dependente. As percepções subjetivas da economia também ofereceram impacto significativo sobre o voto no mandatário. Os dados revelaram, ainda, que as variáveis macroeconômicas aumentam a avaliação positiva da economia (considerada interveniente), que viria a aumentar as chances de eleição do incumbente.

Considerando a importância do indicador econômico para o estudo do voto pautado pela economia, Singer (2013) busca averiguar qual o melhor indicador a ser utilizado ao analisar o voto econômico na América Latina. Em seu trabalho intitulado "Economic Voting in an Era of (Non)Crisis: The Changing Electoral Agenda in Latin America 1982-2010”, o autor recapitula os indicadores comumente utilizados pela literatura internacional, que são: crescimento econômico, inflação e desemprego. Singer pressupõe que os eleitores tendem a se preocupar com assuntos dentro da esfera econômica - que têm apresentado instabilidade recente por causa da pouca atenção dada pelo governo a esses temas, em detrimento de outras políticas econômicas que têm se mostrado mais estáveis. Tal qual sugere Weyland (1998) em seu estudo de caso sobre o Peru, quando sanada uma demanda, o eleitor logo passa a atentar para uma "demanda seguinte", colocando outro problema como sua preocupação central dentro da economia. A ideia que persiste é que a agenda de estudos e indicadores do voto econômico é volúvel e se modifica na medida em que os contextos e - portanto - as preocupações dos eleitores se alteram.

Singer afirma que as eleições da América Latina recentemente apresentaram uma reconfiguração na qual se modificou a centralidade de certos indicadores econômicos. Com o controle da hiperinflação nas décadas de 1980 e 1990, a preocupação passou a voltar-se para outro quesito dentro da economia.

Desse modo, o objetivo do autor é investigar se a atenção do eleitor mudou - isto é, se voltou-se para outro aspecto econômico - após o controle dos preços na América Latina. A hipótese sugerida pelo autor é que essa preocupação, após o controle inflacionário, dirigiu-se para questões não econômicas. Cita, como exemplo, o crescimento da taxa de criminalidade na América Latina, bem como a alta taxa de pobreza. No entanto, a despeito do controle da 
inflação, a insegurança econômica existente na região, a fragilidade da economia em alguns contextos, e devido à experiência do passado com a instabilidade econômica, o desempenho da economia ainda ocupariam certa saliência dentro da esfera de preocupações do eleitor latinoamericano. Outra hipótese é que os eleitores continuam muito preocupados com a economia, porém não mais com a alta dos preços. Em vez disso, dirigem sua preocupação para o crescimento da riqueza do país e o aumento das oportunidades econômicas.

O autor analisou determinantes eleitorais dos resultados de 79 eleições entre 1982 e 2010, valendo-se da série temporal fornecida pelo Latinobarômetro. Os dados foram utilizados de forma agregada.

Os resultados encontrados sugerem que as preocupações mudaram nos últimos trinta anos. Percebe-se que as pessoas tendem a não colocar a alta dos preços ou os seus salários como pressões políticas a serem consideradas centrais, como faziam ao final da década de 1990. Além disso, o crescimento econômico é o fator que mais fortemente impacta o apoio ao partido incumbente entre 2000 e 2010. Os assuntos econômicos assumem papel central dentro das temáticas consideradas importantes. No entanto, as demandas da esfera econômica mudaram no decorrer do período estudado, conforme apontou a hipótese proposta por Singer. O modelo de regressão proposto por Singer para verificar a accountability para economia nas eleições é apresentado do seguinte modo:

\section{SALDO ENTRE OS VOTOS QUE O PARTIDO INCUMBENTE RECEBEU NA ELEIÇÃO ANTERIOR E OS VOTOS QUE O INCUMBENTE RECEBEU NAS ELEIÇÕES UTILIZADAS PARA ANÁLISE = CRESCIMENTO ECONÔMICO + DISPUTA REELEIÇÃO + NÚMERO EFETIVO DE PARTIDOS (NEp) C/ CADEIRAS NA ELEIÇÃO ANTERIOR}

Os resultados indicam que os presidentes no comando de países dotados de economia fraca perderam apoio eleitoral no decorrer do período analisado. Mas os indicadores mudaram através do tempo. A inflação, nos anos 1980, tinha um papel importante ao impactar fortemente o voto no incumbente. O crescimento econômico, no mesmo período, não se mostrou significante. A partir de 2001, contudo, a inflação não tem impacto estatisticamente significativo quando associada ao apoio ao presidente, passando a não ser importante e mostrando que a centralidade dos problemas considerados pelos eleitores assume um caráter contextual. 
Conforme demonstramos, os estudos que transitam nesse campo utilizam tanto dados no nível agregado, quanto dados no nível individual a fim de testarem suas hipóteses. Nesse sentido, há uma discussão na literatura acerca de qual dos dois níveis traria maior poder explicativo às análises empíricas. Kramer (1983) apresentou esse debate com foco no comportamento eleitoral orientado pela economia: com base no estudo de Kinder e Kiewiet (1979a e 1979b apud Kramer, 1983), que aponta uma tendência de superioridade da economia sociotrópica em relação à economia individual, "do bolso" ou egotrópica, Kramer busca fazer uma análise empírica com os dois níveis de dados, intentando identificar qual deles parece ser o mais adequado para a investigação do voto sociotrópico. O que é possível concluir é que os resultados diferem um do outro, ainda que o comportamento eleitoral seja o mesmo. Para o autor, não se pode esperar encontrar os mesmos achados ao utilizar dados em diferentes níveis de mensuração. Tal diferença culmina na conclusão de que os dados em nível agregado representam mais fortemente a realidade.

Admitindo que as inferências de quaisquer tipos de dados serão enviesadas, são os dados agregados que provavelmente produzirão mais inferências válidas, afirma Kramer. No caso desses dados, os vieses são mais modestos e tratáveis. De outro lado, os dados individuais são "contaminados", por dependerem de um valor único de parâmetro e se comportarem de maneira imprevisível: muitas vezes nem sequer apresentam relações com o comportamento individual que se deseja mensurar, chegando, inclusive, a apresentar direções inversas nas relações, por meio de sinais "errados". Por sua vez, os dados agregados tendem a trazer correlações plausíveis, comportando-se na direção esperada.

Com isso, Kramer (1983) deseja mostrar que os dados individuais não são os mais adequados para analisar o efeito das flutuações econômicas no curto prazo no comportamento eleitoral. Apesar de alguns estudos apresentarem inferências válidas geradas por dados desse tipo - conforme será exposto a seguir -, os dados individuais requerem cuidados ao serem modelados, além de necessitarem que se mensurem as nuances e sofisticadas estimações técnicas para que se chegue a resultados válidos dentro dessa temática. Sem isso, resultam apenas estimativas modestas, que muitas vezes não correspondem à verdade.

Com relação à falácia ecológica, o trabalho de Kramer ressalva que, para a operacionalização da hipótese do voto econômico, os dados agregados são mais indicáveis para captar o comportamento individual do que os dados individuais. Isso não quer dizer que não existam estudos que apontem a maior eficácia do uso de dados individuais em outras áreas (a 
literatura da falácia ecológica traz consigo vários exemplos). No entanto, fica claro que, para este tema, os dados agregados parecem trazer resultados mais precisos. Apoiados nessa discussão, utilizaremos dados em nível agregado para testarmos nossas hipóteses.

Além disso, essa seção trouxe a informação de que além dos fatores econômicos, algumas questões de matéria não econômica são importantes para avaliar um líder. O contexto político, a ideologia, variáveis institucionais que permitem a aferição da clareza de responsabilidade em maior ou menor grau seriam alguns exemplos verificados em Samuels (2004), Camargos (2006) e Singer (2013). As variáveis que extrapolam a questão econômica, no entanto, tendem a não apresentar impacto sobre o comportamento eleitoral de forma

recorrente em várias nações ao longo do tempo. Ainda que fatores como crise política e adesão partidária já tenham sido capazes de explicar o comportamento eleitoral em algumas nações (Weyland, 1998 no Peru; Singer, 1998, no caso brasileiro), esse efeito não se mostra tão predominante quanto as variáveis relacionadas à economia. Essas têm apresentado sucesso explicativo em modelos analíticos transnacionais ou mesmo de estudos de caso de longa série temporal.

Ainda no que se refere aos níveis de análise e variáveis que extrapolam a questão econômica para explicar o comportamento eleitoral, é válido ressaltar o papel da variável ideologia nas análises sobre o tema. Conforme demonstrado, a teoria do voto econômico pressupõe que as escolhas eleitorais se baseiam em ação instrumental e estratégica (Riker, 1983 apud Figueiredo, 1988). Isso significa que fatores psicológicos e sociológicos (tais como a ideologia) não são levados em conta no cálculo eleitoral dos cidadãos. Entretanto, a inserção da variável ideologia como uma variável de controle nos estudos do voto econômico foi sugerida por Kramer (1983), que sinalizou a necessidade de incorporação dessa variável por \conta dos resultados das análises de nível individual. Segundo o autor, ao usarem a percepção da economia como variável independente, esses trabalhos de nível micro estariam, provavelmente, considerando avaliações que refletiam a simpatia ou antipatia do eleitor por determinado partido ou mandatário. A variável apareceu em alguns estudos sobre o tema na América Latina (Weyland, 2003; Singer; 2013; Ratto; 2013). Nesse sentido, a variável ideologia (ou identidade partidária) foi incorporada aos estudos que utilizam análises de nível individual como forma de controle. A expectativa nos testes de hipótese do voto econômico é que ela produza impacto irrisório sobre a variável dependente, enquanto as variáveis econômicas devem produzir efeito mais substantivo. Por essa razão (e porque os dados utilizados neste trabalho contam também com dados de nível 
micro, usados de forma agregada) inseriremos também a ideologia como variável de controle em nossas análises.

As análises desenvolvidas neste artigo buscam utilizar as variáveis já trabalhadas pela literatura sobre o voto econômico, mas também intentam contribuir para este tema sugerindo a inserção de novas variáveis para a compreensão do comportamento do eleitor latinoamericano. Para tanto, procuramos adaptar as análises à realidade da região, considerando que as demandas dos cidadãos podem ir além do quesito situação econômica. A incorporação de novas variáveis independentes leva em conta as demandas reconhecidas pelos eleitores. A tabela 1 traz a relação dos seis principais problemas reconhecidos pelos eleitores da região, por ordem de importância. Tais problemas encabeçam uma lista de um total de 29 opções apresentadas aos respondentes do questionário. A relevância dessa informação se pauta no fato de apontar como as variáveis selecionadas para testar o desempenho dos mandatários sobre outros temas relevantes para os latino-americanos representa para a opinião pública uma demanda que exige, de fato, responsividade dos governantes e que, portanto, podem vir a impactar a avaliação do incumbente.

TABELA 1 - Percepção dos Maiores Problemas do País

\begin{tabular}{c|c}
\hline \hline Delinquência/ Segurança Pública & $25 \%$ \\
\hline Desemprego & $24 \%$ \\
\hline A economia/ problemas econômicos/financeiros & $13,9 \%$ \\
\hline Pobreza & $6,8 \%$ \\
\hline Problemas/Situação da Política & $3,7 \%$ \\
\hline \hline Corrupção & $3,5 \%$ \\
\hline \hline
\end{tabular}

Fonte: Latinobarômetro, 2010. N = 21.872 Pergunta: "Em sua opinião, o que você considera ser o maior problema do país?"

Para além da informação, essa tabela nos aponta para a hierarquização feita pelos eleitores latino-americanos sobre a percepção dos principais problemas a atingirem seus países. A segurança pública é enxergada como o principal problema para a maior parte da população. O fato do maior problema considerado por $1 / 4$ dos latino-americanos não dizer respeito à questão econômica já pode nos levar a supor que outros elementos, além dos econômicos, pautam a racionalidade do eleitor da região. Ocorre que, apesar do crescimento econômico na América Latina no período aqui analisado, é possível que tal aumento não tenha sido revertido em bemestar para a população. Ou que, a despeito de ter sido revertido, a população associe a melhora de vida a outros fatores, como fruto do esforço individual, por exemplo. 
Assim, as variáveis clássicas do estudo do voto econômico: taxa do PIB, taxa da inflação e taxa de desemprego, para estudos agregados e avaliação da economia (individual ou nacional, retrospectiva ou prospectiva) para estudos de dados individuais, pode não captar a percepção da opinião pública da América Latina sobre a melhora de vida em seu dia a dia. Voltando os olhos para a tabela 1, lembramos que a própria pobreza, que é percebida como um dos principais problemas da região, tem raízes em questões econômicas, mas não é combatida apenas com o crescimento econômico. Políticas sociais são fundamentais para este combate. Da mesma forma que adoção de políticas específicas para a redução do desemprego, outro fator econômico, podem ser percebidas como mais ou menos bem-sucedidas pelo eleitorado. O mesmo vale para a corrupção, que também exige políticas de enfrentamento. As crises econômicas, enquanto pertencentes ao terceiro lugar do ranking tornam claro que não podemos ignorar as outras demandas sociais como possibilidades a impactar a avaliação positiva dos líderes. Com isso utilizamos como variáveis independentes a percepção do desempenho dos incumbentes diante dessas questões: avaliação do desempenho do presidente na atuação sobre políticas públicas e de combate à corrupção ${ }^{4}$.

\section{HIPÓTESES}

Pautados na literatura, e buscando adaptar a teoria do voto econômico para a realidade latino-americana, formulamos o conjunto de hipóteses abaixo. Conforme demonstramos pela tabela 1, é impossível falar em avaliação retrospectiva na América Latina sem que se leve em consideração outros fatores além da economia como vem sendo analisada até aqui (com dados como crescimento do PIB, inflação e desemprego ou avaliação da economia por meio de surveys). Assim, consideramos relevante levar em conta não apenas a situação econômica, mas também a percepção e atuação do governo sobre políticas públicas e de combate à corrupção.

\footnotetext{
4 Por limitações de dados, o desempenho do presidente no combate ao desemprego não pôde ser mensurado, posto que essa pergunta não esteve presente em todos os questionários/banco de dados utilizados e a opção pela incorporação desta variável diminuiria sensivelmente o tamanho de nossa amostra.
} 


\section{H1 - Avaliações subjetivas do eleitor impactam na avaliação positiva do presidente}

Ao olharmos para o que os cidadãos latino-americanos consideram como principais tópicos relevantes da agenda política da região, é possível supor que a melhora na economia (por meio do crescimento ou redução da inflação) não são suficientes para que os eleitores considerem que o presidente está fazendo um bom trabalho. Através do que já nos apontou a literatura da área (Weyland, 1998; 2000; 2003; Camargos, 1999; Carreirão, 1999; Echegaray, 2005) e olhando para a relevância das variáveis subjetivas escolhidas para representar as grandes preocupações do eleitor latino-americano (conforme apontado na tabela 1), partimos da hipótese de que quanto mais altas forem as avaliações subjetivas acerca da economia e do desempenho do presidente sobre políticas públicas e de combate à corrupção, mais altas seriam também as avaliações positivas do mandatário. As variáveis subjetivas se mostrariam preditoras da avaliação do incumbente, corroborando com a hipótese do voto econômico e, ainda, avançando com avaliações em matérias não econômicas.

\section{H2 - Os dados objetivos impactam a avaliação positiva do presidente}

Tal como nos mostra literatura, os dados objetivos referentes à economia impactam a avaliação do presidente (Remmer, 1991; Samuels, 1994; Arce e Carrión, 2010; Lewis-Beck e Ratto, 2013). Baseando-nos nesse argumento, temos o intuito de demonstrar a existência do voto econômico na América Latina e, para isso, partimos da hipótese de que dados objetivos de crescimento econômico, de investimento em políticas públicas e referentes à transparência do governo dialogam com as demandas eleitorais expostas na tabela 1. Apesar da falta de dados objetivos que expressem ações diretas em prol da segurança, esperamos que esses dados reflitam as preocupações dos eleitores e, assim: quanto maior o PIB, quanto maior o investimento social e quanto mais transparente for o governo no que se refere à corrupção, mais alta será a avaliação do incumbente. Espera-se que haja entre tais variáveis uma correlação estatisticamente significativa.

\section{H3 - O impacto da ideologia na avaliação do presidente}

A ideologia aparece em nossos modelos como variável de controle. A expectativa é que tal variável apresente contribuição irrisória sobre a variação da avaliação do presidente. No entanto, 
Cadernos de Estudos Sociais e Políticos, Rio de Janeiro, vol. 7, n 12, 2017

em caso de impacto, esperamos que a ideologia alinhada à ideologia do presidente avaliado venha a impactar a avaliação positiva do mesmo. 


\section{METODOLOGIA}

O principal objetivo deste trabalho é identificar o que pesa na avaliação positiva dos presidentes da América Latina. Para isto, trabalhamos com dados agregados referentes a 36 mandatos. Para a formação do banco de dados agregados utilizamos resultados de pesquisa de opinião oriundas do Barômetro das Américas, informações coletadas junto ao CEPAL (Comisión Económica para América Latina y Caribe) e ao Transparency International. Todas as variáveis selecionadas para explicar a avaliação positiva do presidente foram escolhidas pautadas na teoria do voto econômico. Tal teoria pautou, também, a justificativa para a inserção de outros aspectos relevantes para o eleitor, que também são importantes para a avaliação retrospectiva de um presidente latino-americano. A seguir, apresentaremos nossas variáveis, e análises.

\section{VARIÁVEL DEPENDENTE}

A avaliação positiva do presidente foi selecionada como variável dependente. De acordo com Lewis-Beck e Stegmaier (2008), duas variáveis dependentes são comumente utilizadas para os estudos do voto econômico: a) voto no incumbente ou b) avaliação do presidente. A maior parte dos estudos que utilizam a avaliação do presidente como variável dependente na América Latina são os estudos de caso (Weyland, 1998, 2000, 2003). Nesse sentido, há demanda para resultados sobre o tema baseados nesta variável. Além disso, essa escolha também se justifica por questões metodológicas. Isso porque as variáveis de nível individual, relativas à avaliação do desempenho do presidente sobre políticas públicas em prol da democracia e de combate à corrupção (fatores que consideramos ricos e que convergem com a contribuição que aqui procuramos fazer) estavam presentes apenas na pesquisa do Barômetro das Américas, que não conta com a variável voto. Por essa razão optamos por utilizar a variável avaliação do presidente. De acordo com alguns pesquisadores da área, é possível identificar na avaliação do presidente um passo necessário ao voto, o que permite esta variável estar do lado esquerdo da equação (Camargos, 2006; Lewis-Beck e Stegmaier, 2008). Com isso, acredita-se que a avaliação positiva do presidente deve levar ao voto no (partido ou candidato) incumbente. É partindo dessa 
premissa que consideramos que essa variável cumpre o propósito para este estudo sobre voto econômico.

A intenção foi analisar a avaliação do desempenho do presidente nos dois últimos mandatos de 18 países latino-americanos. Isto quer dizer que por conta do processo de reeleição em alguns países avaliamos o desempenho de apenas um presidente (se reeleito) e em outros o desempenho de dois presidentes (caso não tenha havido reeleição). Os presidentes em análise constam na tabela/anexo 1.

Para tal foram utilizados os surveys do Barômetro das Américas referente aos 18 países. O survey coordenado pela Universidade de Vanderbilt teve a sua primeira rodada em 2004. Considerando este limite para a disponibilidade dos dados, colocamos este ano como marco inicial para abrangência desta pesquisa. Isto quer dizer que todos os presidentes analisados tiveram o seu mandato iniciado após 2004. A escolha da data/rodada da pesquisa a ser utilizada obedeceu ao seguinte critério: preferencialmente, buscou-se utilizar a rodada de pesquisa que coincidia com o segundo ano de mandato do presidente. O objetivo era fazer com que fosse tomada uma avaliação do desempenho do mandatário após mais de um ano de seu mandato, contudo ainda com baixa interferência da próxima disputa eleitoral. Neste caso se enquadraram 11 casos. No entanto, como os questionários do Barômetro das Américas são aplicados bianualmente (excetuando o caso da Colômbia, onde as rodadas são anuais), algumas adaptações tiveram de ser feitas em alguns casos. Isto porque, em algumas situações, o segundo ano de mandato do presidente coincidia com o ano de ausência de pesquisa de campo do Barômetro das Américas. Nestes casos, buscou-se adotar os surveys que correspondiam ao terceiro ano de mandato. Desta forma, mantinham-se as condições iniciais de avaliação de desempenho do mandatário após um ano de sua posse, contudo sem a presença da forte pressão eleitoral. Nesta situação se enquadraram 21 casos. Em apenas três casos não foi possível manter o padrão mencionado acima. Mas os três casos se referiam à reeleição de presidentes e, portanto, os mandatários avaliados em seu primeiro ano de governo já eram conhecidos dos entrevistados previamente. Há, ainda, um único caso referente ao Paraguai que não satisfez essas condições, para o qual tivemos de utilizar o banco de dados referente ao seu último ano de mandato.

A pergunta utilizada para identificação da variável dependente foi: Falando em geral do atual governo, como o(a) sr./sra. avalia o trabalho que o/ a Presidente X está realizando? As opções de respostas eram "muito bom"; "bom"; "nem bom, nem mau (regular)"; "mau”; "muito mau (péssimo)"; "não sabe" e, ainda, "não respondeu". Para montar o banco de dados agregados que deu origem 
às análises aqui desenvolvidas, foi considerada como avaliação positiva do presidente a soma da porcentagem dos respondentes às categorias "bom" e "muito bom", gerando variável contínua, que passou a constituir o banco de dados agregados, assim como as demais variáveis utilizadas no banco.

\section{VARIÁVEIS INDEPENDENTES}

Dez variáveis foram pensadas para explicar a variação da avaliação positiva dos presidentes da América Latina entre os anos de 2004 e 2012. A escolha dessas, ancorada na literatura, auxiliou, também, na opção pelo Barômetro das Américas, em detrimento de outros bancos de dados como Latinobarômetro ou Comparative Studies of Electoral System - CSES que não ofereciam as questões que se mostraram relevantes de se testar empiricamente, o período de aplicação dos surveys não era satisfatório e/ou número de casos mais restritos. Além dos dados provenientes do Barômetro das Américas, foram utilizados, ainda, dados do CEPAL, e da Transparency International para formar o conjunto de variáveis independentes. Quais sejam:

a) Avaliações subjetivas do desempenho econômico (retrospectiva): avaliação da economia retrospectiva sociotrópica;

b) Avaliação subjetiva do desempenho do presidente no que se refere a políticas públicas e temas relevantes da agenda política da América Latina: avaliação do combate à pobreza, avaliação do combate à corrupção, avaliação do respeito e promoção de princípios democráticos, avaliação da melhora da segurança cidadã;

c) Dado objetivo de economia: produto interno bruto (PIB) por habitante em dólar ${ }^{5}$;

d) Posicionamento no espectro ideológico: auto-posicionamento ideológico por parte da opinião pública alinhado à ideologia do incumbente ${ }^{6}$;

5 Entre os três indicadores econômicos tradicionalmente utilizados para mensurar a economia inflação, PIB e desemprego - , elegemos o PIB como principal dado econômico objetivo para essa pesquisa porque, conforme nos indica Singer (2013), a inflação e o desemprego perderam a centralidade entre a preocupação dos eleitores a partir do ano 2000, cedendo ao PIB o referido protagonismo.

6 Entre os três indicadores econômicos tradicionalmente utilizados para mensurar a economia inflação, PIB e desemprego - , elegemos o PIB como principal dado econômico objetivo para essa 
e) Desempenho social: gasto público social por habitante; e

f) Índice de percepção da corrupção.

\section{ANÁLISES}

\section{ANÁLISE FATORIAL}

Para esta primeira análise foram selecionadas nove variáveis. Pelo fato das avaliações da economia estarem fortemente correlacionadas (e buscando evitar o problema de multicolinearidade), optamos por excluir uma delas. Como a avaliação da economia sociotrópica apresentou maior correlação com a nossa variável dependente do que a avaliação da economia individual, foi essa última a escolhida para ser retirada do modelo. As correlações entre as demais variáveis não apresentaram problemas que pudessem interferir na continuação das análises.

Na solução fatorial posterior à rotação Varimax, é possível perceber que os fatores são compostos por distintos números de variáveis. O fator um, foi composto, quais sejam: (1) avaliação positiva do presidente no que se refere ao desempenho no combate à pobreza; (2) avaliação positiva do presidente no que se refere à proteção e promoção dos princípios democráticos; (3) avaliação positiva do presidente em seu desempenho no combate à corrupção; (4) avaliação positiva da atuação do presidente na proteção da segurança do cidadão; e (5) avaliação retrospectiva da economia sociotrópica. O fator dois agregou três variáveis: (1) gasto público social por habitante; (2) índice de percepção da corrupção; e (3) PIB por habitante em dólar. E o fator três é composto por uma variável, que é ideologia do eleitor. O conteúdo das variáveis agrupadas por meio da análise fatorial aponta para uma classificação. A distribuição dos fatores pode ser compreendida do seguinte modo: fator um - que chamaremos a partir daqui de "percepção do desempenho", fator dois - nomeado como "aspectos objetivos do desempenho", e fator três - representando o que cunhamos de "ideologia dos eleitores alinhada à ideologia do presidente". É a partir desses três fatores que faremos a regressão exposta a seguir.

pesquisa porque, conforme nos indica Singer (2013), a inflação e o desemprego perderam a centralidade entre a preocupação dos eleitores a partir do ano 2000, cedendo ao PIB o referido protagonismo. 


\section{MODELOS DE REGRESSÃO}

O modelo de regressão escolhido para este estudo é o de regressão hierárquica. A intenção de adotar a regressão hierárquica é separar o impacto de cada agrupamento de variável independente na variável dependente de acordo com a lógica do modelo causal. A ideia é compreender como se dá o impacto das variáveis exógenas e endógenas, separadamente. Isso também é relevante para percebermos como se comportam os dados, objetivos ou os referentes à percepção na relação com a variável dependente. A demonstração de um modelo de cada vez se dá a fim de elucidar de forma mais clara as expectativas do modelo causal, baseado em variáveis exógenas e endógenas.

Para atingir essa meta o primeiro passo será remover as variáveis intervenientes (que é o fator "percepção de desempenho") do modelo total. Para: 1) estimar o modelo reduzido com o impacto da variável independente exógena (que é composta pelo fator "aspectos objetivos do desempenho" e pelo fator "ideologia dos eleitores alinhada à ideologia do presidente") na variável dependente; 2) calcular a contribuição exclusiva das variáveis endógenas na variável dependente.

Com isso, em nosso primeiro modelo de regressão esperamos verificar impacto significativo dos "aspectos objetivos do desempenho", bem como da "ideologia alinhada à ideologia do presidente" na avaliação positiva do presidente. Ou seja, quando o PIB; o gasto público social; o índice de percepção da corrupção e, ainda, o percentual ideologia alinhada à ideologia do presidente (componentes dos fatores dois e três) aumentarem, que aumente também a avaliação positiva do presidente de modo estatisticamente significativo. O modelo pode ser representado graficamente desse modo:

FIGURA 1 - Modelo Impacto das Variáveis Exógenas (Modelo 1A)

\section{VARIÁVEIS EXÓGENAS}

Aspectos objetivos do desempenho

(Fator 2)

Ideologia (Fator 3)
AVALIAÇÃO POSITIVA DO PRESIDENTE 
O resultado do modelo reduzido mostra que as duas variáveis independentes têm seu efeito na direção esperada. Isto é, quanto maior o fator "aspectos objetivos do desempenho" e quanto maior o fator "ideologia dos eleitores alinhada à ideologia dos presidentes", maior a avaliação positiva do presidente. $\mathrm{O}$ efeito de ambas as variáveis, contudo, não é significativo. $\mathrm{Ou}$ seja, elas não têm nenhum impacto direto estatisticamente significante na avaliação positiva do presidente.

Isso significa que nossa primeira hipótese não se confirma, porque não há nenhum impacto do fator "aspectos objetivos do desempenho" e do o fator "ideologia dos eleitores alinhada à ideologia dos presidentes" na avaliação positiva do presidente.

TABELA 2 - Modelo 1A

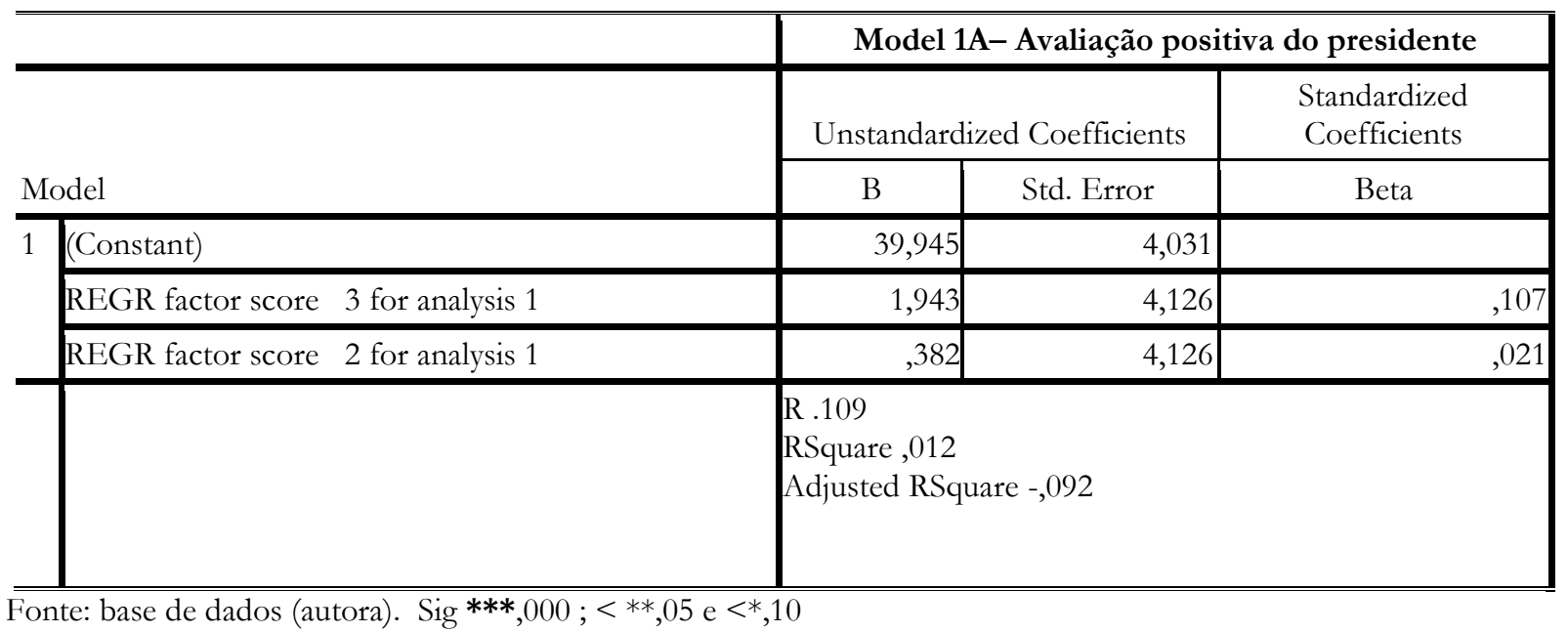

Seguimos, então, para o passo onde intentamos verificar o peso do fator um - "percepção do desempenho" - na variável dependente. Isolamos, portanto, os fatores dois e três, e o modelo de regressão apresentado a seguir é composto da seguinte maneira:

FIGURA 2 - Modelo Impacto da Variável Endógena (Modelo 2A)

\section{VARIÁVEL ENDÓGENA}

Percepção do Desempenho

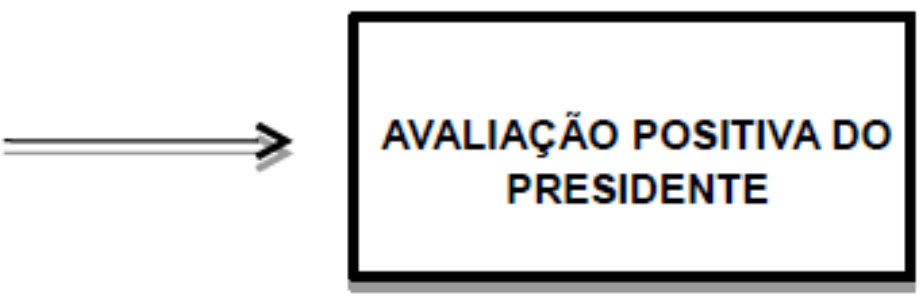


Esperamos verificar, aqui, uma correlação significativa entre o fator "percepção do desempenho" e a nossa variável dependente. Sendo assim, quanto mais bem avaliados forem a economia retrospectiva e o desempenho do presidente no que se refere a políticas públicas e temas relevantes na agenda da América Latina (variáveis essas que compõem o fator um), será também melhor avaliado o mandatário.

Verificamos que o fator "percepção do desempenho" tem o efeito na direção esperada que é quanto maior a "percepção do desempenho", maior a avaliação positiva do presidente. E este efeito é estatisticamente significativo.

Assim a nossa segunda hipótese, que propõe que o aumento do fator "percepção do desempenho" conduz ao aumento da avaliação positiva do presidente se confirma.

TABELA 3 - Modelo 2A

\begin{tabular}{|c|c|c|c|c|}
\hline & & \multicolumn{3}{|c|}{ Model 2A- Avaliação positiva do presidente } \\
\hline & & \multicolumn{2}{|c|}{ Unstandardized Coefficients } & $\begin{array}{l}\text { Standardized } \\
\text { Coefficients }\end{array}$ \\
\hline \multicolumn{2}{|c|}{ Model } & B & Std. Error & Beta \\
\hline \multirow[t]{3}{*}{1} & (Constant) & 39,945 & 1,899 & \\
\hline & REGR factor score 1 for analysis 1 & $15,867 * * *$ & 1,943 &, $877^{* * *}$ \\
\hline & & \multicolumn{3}{|c|}{$\begin{array}{l}\mathrm{R}, 877 \\
\text { RSquare ,769 } \\
\text { Adjusted RSquare, } 758\end{array}$} \\
\hline
\end{tabular}

No próximo estágio avaliaremos o efeito de todas as variáveis independentes na variável dependente. Isto é, o impacto dos três fatores na avaliação positiva do presidente. Nesse modelo total, espera-se que todos os fatores apresentem impacto significativo e que, dessa forma, tanto a "percepção do desempenho", quanto os "aspectos objetivos do desempenho", e também a "ideologia alinhada à ideologia do presidente" apresentem uma relação significativa com a avaliação positiva do presidente. O modelo se formará da seguinte maneira:

FIGURA 3 - Modelo Total (Modelo 3A) 


\section{"Percepção do desempenho" (Fator 1) \\ "Aspectos objetivos do desempenho" (Fator 2) \\ Ideologia alinhada à ideologia do presidente" (Fator 3)}

O resultado do modelo mostra que todas as variáveis têm o seu efeito na direção esperada, ou seja, quanto maior a "percepção do desempenho", os "aspectos objetivos do desempenho" e a "ideologia alinhada à ideologia do presidente", maior será a avaliação positiva do presidente. Contudo, só o fator "percepção do desempenho" é estatisticamente significativo, o que quer dizer que, no modelo total, somente a "percepção do desempenho" oferece poder explicativo ao modelo, impactando na avaliação positiva do presidente.

TABELA 4 - Modelo 3A

\begin{tabular}{|c|c|c|c|c|}
\hline & & \multicolumn{3}{|c|}{ Model 3A- Avaliação positiva do presidente } \\
\hline & & \multicolumn{2}{|c|}{ Unstandardized Coefficients } & \multirow{2}{*}{$\begin{array}{c}\begin{array}{c}\text { Standardized } \\
\text { Coefficients }\end{array} \\
\text { Beta }\end{array}$} \\
\hline \multicolumn{2}{|c|}{ Model } & $\mathrm{B}$ & Std. Error & \\
\hline \multirow[t]{4}{*}{1} & (Constant) & 39,945 & 1,949 & \\
\hline & REGR factor score 1 for analysis 1 & $15,867 * * *$ & 1,995 &, $877 * * *$ \\
\hline & REGR factor score 2 for analysis 1 & ,382 & 1,995 & ,021 \\
\hline & REGR factor score 3 for analysis 1 & 1,943 & 1,995 & 107 \\
\hline & & \multicolumn{3}{|c|}{$\begin{array}{l}\mathrm{R}, 884 \\
\text { RSquare ,781 } \\
\text { Adjusted RSquare ,745 }\end{array}$} \\
\hline
\end{tabular}

Fonte: base de dados (autora).

Sig $* * *, 000 ;<* *, 05$ e $<*, 10$

Considerando os resultados, o próximo passo foi verificar o impacto das variáveis objetivas de desempenho e da ideologia no fator um - "percepção do desempenho". Com essa regressão espera-se observar o impacto significativo das variáveis exógenas na variável endógena. Assim, intentamos verificar se, a despeito de os fatores dois e três não se demonstrarem significativos no modelo total, não há chances de a percepção do desempenho ser resultado das 
variáveis objetivas e também da ideologia. Se, de fato for, verificaremos que as variáveis exógenas impactariam a avaliação positiva do presidente latino-americano de modo indireto.

Para essa etapa o fator dois "aspectos objetivos do desempenho" será desarticulado nas variáveis que o compõe (gasto social por habitante, índice de percepção da corrupção e PIB por habitante). E o fator três, "ideologia alinhada à ideologia do presidente", também será desarticulado, e adotaremos diretamente a variável. O desmembramento dos fatores e adoção da variável foi uma medida justificável pelo fato de a análise fatorial baseada na rotação de Varimax rotated factor assumir correlação zero entre as dimensões, o que impede o teste de mostrar o quanto uma dimensão explica outra dimensão (Figueiredo Filho e Silva Jr., 2010).

O modelo será construído da seguinte forma:

FIGURA 4 - Modelo Impacto das V. Exógenas na V. Endógena (Modelo 4A)

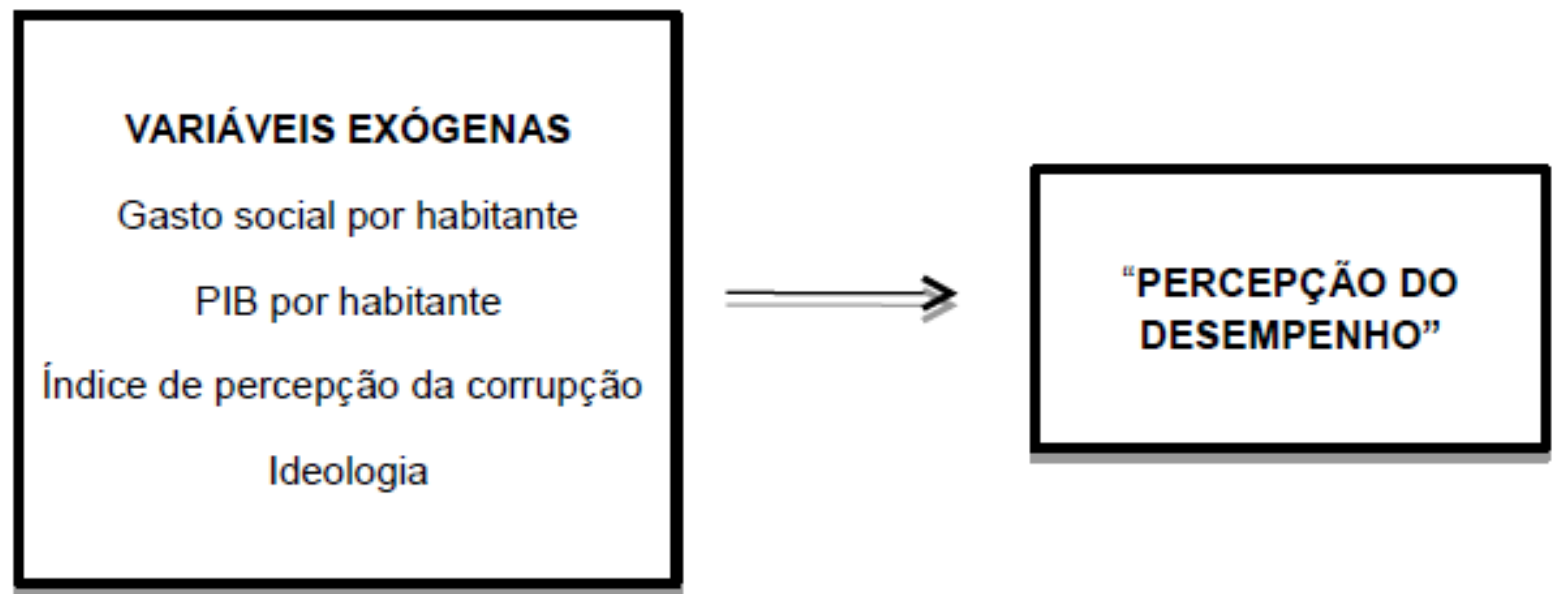

Ao rodarmos a regressão a variável gasto público social por habitante foi excluída do modelo pelo método stepwise. O efeito da percepção da corrupção, da ideologia e do PIB por habitante demostraram efeito no sentido esperado, ou seja quanto maior o PIB, quanto mais próxima a ideologia e a transparência, maior a avaliação positiva do presidente. Contudo, quando a ideologia está presente no modelo, o PIB perde o impacto significativo. Com isso, adotamos o modelo o qual não consta ideologia, onde o PIB é significativo (sig $>, 10$ ) e também é significativo índice de percepção da corrupção (sig > ,05).

Assim a nossa terceira hipótese de que os componentes exógenos impactariam as variáveis intervenientes é apenas parcialmente confirmada, pois se o índice de percepção da corrupção e o PIB por habitante se demonstraram estatisticamente significantes, a ideologia não se mostrou, bem como o gasto público social por habitante, que foi excluído do modelo. Nossa 
Cadernos de Estudos Sociais e Políticos, Rio de Janeiro, vol. 7, n 12, 2017

análise sugere que a percepção da corrupção foi um preditor mais forte do que o PIB por habitante. Contudo, esse modelo indica o impacto de duas variáveis objetivas na "percepção do desempenho" do eleitor.. 
TABELA 5 - Modelo 4A

\begin{tabular}{|c|c|c|c|c|}
\hline & & \multicolumn{3}{|c|}{ Model 4A- Fator 1 - Percepção do Desempenho } \\
\hline & & \multicolumn{2}{|c|}{ Unstandardized Coefficients } & \multirow{2}{*}{$\begin{array}{c}\begin{array}{c}\text { Standardized } \\
\text { Coefficients }\end{array} \\
\text { Beta }\end{array}$} \\
\hline \multicolumn{2}{|c|}{ Model } & B & Std. Error & \\
\hline \multirow[t]{4}{*}{1} & (Constant) &,- 657 &, 513 & \\
\hline & Percepção da corrupção &, $039 * *$ & 018 &, $641 * *$ \\
\hline & PIB por habitante em dólares & ,000* & 000 &,$- 506^{*}$ \\
\hline & & \multicolumn{3}{|c|}{$\begin{array}{l}\mathrm{R}, 454 \\
\text { RSquare ,206 } \\
\text { Adjusted RSquare ,122 }\end{array}$} \\
\hline
\end{tabular}

Fonte: base de dados (autora). Sig $* * *, 000 ;<* *, 05$ e $<*, 10$

Dentre os modelos de regressão apresentados anteriormente, poderíamos usar para esse trabalho o modelo $3 \mathrm{~A}$, que é o modelo total; ou os modelos $2 \mathrm{~A}$, que verifica o impacto da variável endógena em adição ao $4 \mathrm{~A}$, que verifica o impacto das variáveis exógenas na variável endógena como indicadores da regressão hierárquica. Optamos pela segunda possibilidade posto que consideramos que essa oferece um maior poder explicativo, enriquecendo a nossa análise. Isso porque, como vimos, no modelo total as variáveis exógenas não impactam significativamente a variável dependente e, assim, a "ideologia alinhada à ideologia do presidente" e os "aspectos objetivos do desempenho" se demonstram irrelevantes na avaliação positiva do presidente. No entanto, através da regressão hierárquica foi possível identificarmos algumas minúcias ignoradas nos resultados do modelo total. Quando utilizamos a "percepção do desempenho" como variável dependente, percebemos que o PIB por habitante e o índice de percepção da corrupção (variáveis que compuseram o conjunto de variáveis exógenas) contribuem de modo significativo para a "percepção do desempenho". Ou seja, apesar de o PIB e o índice de percepção da corrupção não impactarem a avaliação do incumbente, essas variáveis contribuem para a construção de preferências e avaliações subjetivas feitas pelo eleitor latinoamericano. Isso significa que há um impacto indireto dessas variáveis na avaliação positiva do presidente. Com isso, a adoção da regressão hierárquica para esse trabalho, aponta para a seguinte noção: 


\section{FIGURA 5 - Modelo Causal Hierárquico}
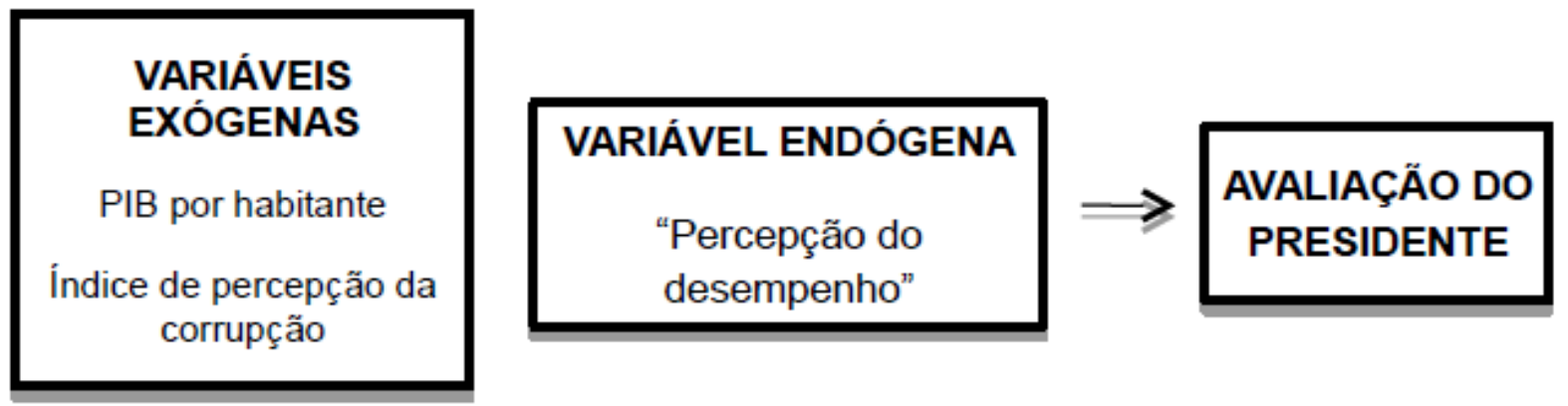

A seguir teceremos algumas considerações finais sobre a investigação aqui realizada, apontando para desafios futuros dessa área de pesquisa.

\section{CONCLUSÕES}

Essa pesquisa inseriu-se no debate teórico acerca do voto econômico que apontava demandas específicas: a principal delas, apontada por Lewis-Beck e Stegmeier (2008), estava relacionada à dúvida sobre a presença do voto econômico em democracias transicionais. Os autores também ressaltaram a carência de estudos de nível transnacional que operacionalizassem a hipótese do voto econômico lançando mão da avaliação do presidente como variável dependente. Buscando preencher essa lacuna, desenvolvemos este estudo.

Apresentamos nove variáveis independentes que de acordo com a literatura poderiam se mostrar eficientes para explicar a avaliação positiva do presidente latino-americano. Com o intuito de diminuir o número de variáveis e de agrupá-las de acordo com sua proximidade, aproximando variáveis que possuem a mesma estrutura subjacente (Tabachinick e Fidell, 2007 apud Figueiredo Filho. e Silva Jr., 2010), optamos por fazer análise fatorial e, a partir dos fatores gerados, organizamos nosso modelo de regressão hierárquica. A análise fatorial exploratória, utilizada para este estudo, buscou identificar padrões de correlação entre as variáveis independentes. Essa técnica, segundo Figueiredo Filho e Silva Jr. (2010), é interessante para pesquisas em estágio inicial, pois auxilia no norte do decorrer do estudo. Assim, foram gerados três fatores: fator um "percepção do desempenho", fator dois "aspectos objetivos do desempenho" e fator três "ideologia dos eleitores alinhada à ideologia do presidente". O modelo 
total de regressão hierárquica compreendeu as variáveis (desarticuladas dos fatores 2 e 3) PIB e índice de percepção da corrupção, compreendidos como variáveis exógenas. O fator um, "percepção subjetiva do desempenho" foi compreendido como variável endógena, isto é, variável interveniente a impactar a avaliação positiva do presidente. Esses fatores aliados vêm a explicar, segundo o modelo de regressão, 78\% da avaliação positiva do presidente latino-americano (R Square: ,781).

Ao realizarmos outros testes de regressão, intentando verificar o impacto das variáveis exógenas na variável endógena, bem como o impacto da variável endógena na variável dependente constatamos que o índice de percepção da corrupção e o PIB oferecem algum impacto para "percepção subjetiva do desempenho" (fator um), reforçando o seu caráter interveniente. Ou seja, apesar de o PIB e o índice de percepção da corrupção não impactarem a avaliação do incumbente, essas variáveis contribuem para a construção de preferências e avaliações subjetivas feitas pelo eleitor latino-americano. Isso significa que há um impacto indireto dessas variáveis na avaliação positiva do presidente.

Para os estudiosos interessados no voto econômico, essa investigação sugere que, além dos indicadores econômicos, os eleitores também podem vir a produzir respostas efetivas ao desempenho do presidente na condução de políticas públicas e de combate à corrupção. Isso também denota uma postura satisfacionista, já que os eleitores que percebem um bom desempenho do mandatário o avaliam de forma positiva, e o contrário também é verdade. Assim, a inserção de variáveis que mensuram avaliação do desempenho do presidente sobre políticas públicas e de combate à corrupção pode vir a contribuir para a compreensão dos determinantes do comportamento eleitoral. Interessante lembrar ainda da ausência do impacto da variável ideologia, indicando mais uma vez que o comportamento racional se dá de modo independente em relação ao posicionamento ideológico; provavelmente mais focado em questões específicas, como elucidaram Dalson e Kleingmann (2009).

Para os estudiosos interessados na América Latina, a contribuição desse trabalho se centra na possibilidade de afirmar o peso da avaliação retrospectiva do desempenho sobre economia e políticas públicas e de combate à corrupção na avaliação do presidente no passado recente do cenário político latino-americano. Respondendo às indagações da literatura internacional a respeito da existência de sofisticação do eleitor em democracias jovens que vivenciaram amplo contexto de crise, os resultados presentes nesse estudo indicam que o eleitor da região é dotado de capacidade de responsabilizar o seu governante por sua conduta enquanto 
incumbente. A base dessa responsabilização se encontra tanto em questões de matéria econômica quanto em questões de matéria não econômicas que, conforme vimos, ocupam relevante centralidade entre as preocupações dos latino-americanos.

A despeito de termos verificado algum impacto de variáveis objetivas como PIB e índice de percepção da corrupção na "percepção do desempenho do mandatário", essa relação ainda pode ser explorada em estudos futuros, dentro dessa agenda de pesquisa. Considerando que não há impacto das variáveis objetivas na avaliação positiva do presidente, é importante que se verifique quais outras variáveis contribuem para a "percepção do desempenho" de maneira mais substantiva. Uma possível explicação para esse descompasso entre as variáveis subjetivas e objetivas e seu impacto sobre a variável dependente pode ser o grau de informação por parte do eleitor; ou ainda o grau de liberdade de imprensa de que são dotados os países em análise. Enfim, essas são hipóteses passíveis de serem testadas que apontam para um frutífero e merecedor de atenção campo de estudo que pode ser desenvolvido com base nas contribuições desse estudo.

Submetido para avaliação em 09 de Abril de 2018 Aprovado para publicação em 10 de Junho de 2018

\section{BIBLIOGRAFIA}

BARONE, L. S. (2009). Responsabilização política nos estados brasileiros: o voto econômico nas eleições para governador. Dissertação de mestrado. Escola de Administração de Empresas de São Paulo da Fundação Getúlio Vargas.

CAMARGOS, M. (2006). Economia e eleições na América Latina: Refinando a teoria do Voto Econômico. In Anais 30. Encontro Anual da ANPOCS.

CARREIRÃO, Y. (1999) Avaliação do Governo e "Voto Econômico". Lua Nova, n 48, São Paulo, pp.213-145, dez.

DALTON, R.; KLINGEMANN, H. D. (2009). Citizens and Political Behavior, in DALTON, R.; KLINGEMANN, H. D (org). The Oxford Handbooks of Political Science, Oxford: Oxford University. 
FIGUEIREDO FILHO, D. B., \& SILVA JUNIOR, J. A. (2010). Visão além do alcance: uma introdução à análise fatorial. Opinião Pública, Campinas, 16 (1), 160-185.

ECHEGARAY, F. (2005) Economic Crises and Electoral Responses in Latin America. Lanhan: University Press of America.

FIGUEIREDO, M. (1998). Democracia, comportamento eleitoral e racionalidade do voto. Tese de Doutorado. São Paulo. USP.

LEWIS-BECK, Michael; STEGMAIER, Mary. (2008) The Economic Vote in transitional democracies. Journal of Elections, Public Opinion \& Parties, V. 18:3, pp.303-323.

KRAMER, G. H. (1983). The Ecological Fallacy Revisited: Aggregate vs. Individual-Level Findings on Economics and Elections, and Sociotropic Voting. American Political Science Review 65, 131-143.

PEIXOTO, V.; RENNÓ, L. (2011). Mobilidade social ascendente e voto: as eleições presidenciais de 2010 no Brasil. Opinião Pública, v. 17, n 2, 304-332

REMMER, K. (1991). The political impact of economic crisis in Latin America in the 1980s. American Political Science Review, 85, 777-800.

RATTO, M. C. (2013). Accountability y voto económico en América Latina: Um estudio de las pautas de comportamento eleitoral entre 1996-2004. Revista Mexicana de Análisis Politico y Administración Pública, v. 2, n. 1, p.49.

SAMUELS, D. (2004). Presidentialism and Accountability for Economy in Comparative Perspective. American Political Science Review, v. 98, n. 3, agosto pp.425-436.

SINGER, A. (2000). Esquerda e direita no eleitorado brasileiro. São Paulo: EDUSP.

SINGER, M. (2013). Economic Voting in an Era of (Non) Crisis: The Changing Electoral Agenda in Latin America 1982 - 2010. Comparative Politics, 45 (2), 169-185.

VEIGA, L. (2013) Economic Voting in an Age of Growth and Poverty Reduction: Electoral Response in Latin America (1995-2010). CSD Working Papers, Center for the Study of Democracy UC Irvine. Link: http://www.escholarship.org/uc/item/8r683983.

VEIGA, L; DUTT-ROSS, S. (2016). Os determinantes da avaliação da economia na eleição presidencial brasileira em 2014. Opinião Pública, v. 22, n. 3, p. 524-549.

WEYLAND, K. (1998). Peasants or Bankers in Venezuela? Presidential Popularity and Economic Reform Approval,1989-1993. Political Research Quarterly, 51 (2), 341-362.

(2000). A Paradox of Success? Determinants of political support for President Fujimori. International Studies Quarterly, n. 44, p. 481-502. 
Cadernos de Estudos Sociais e Políticos, Rio de Janeiro, vol. 7, nº 12, 2017

(2002). Economic Voting Reconsidered: Crisis and Charisma in the Election of Hugo Chávez. Comparative Political Studies, v. 36, n 7, p.822-848, setembro. 


\section{ANEXOS}

ANEXO 1: Tabela 1 - Presidentes sob análise

\begin{tabular}{|c|c|c|}
\hline País & Início do Mandato & Presidente \\
\hline Argentina & 2007 & Cristina Fernández de Kirchner \\
\hline Argentina & 2011 & Cristina Fernández de Kirchner \\
\hline Bolívia & 2006 & Juan Evo Morales \\
\hline Bolívia & 2009 & Juan Evo Morales \\
\hline Brasil & 2006 & Luiz Inácio Lula da Silva \\
\hline Brasil & 2010 & Dilma Rousseff \\
\hline Chile & 2006 & Michele Bachelet \\
\hline Chile & 2010 & Miguel Juan Piñera \\
\hline Colômbia & 2006 & Álvaro Uribe Vélez \\
\hline Colômbia & 2010 & Juan Manuel Santos Calderón \\
\hline Costa Rica & 2006 & Óscar Rafael Sánchez \\
\hline Costa Rica & 2010 & Laura Chinchilla Miranda \\
\hline El Salvador & 2004 & Elias AntonioSaca González \\
\hline El Salvador & 2009 & Carlos Mauricio Funes Cartagena \\
\hline Equador & 2004 & Alfredo Palacio \\
\hline Equador & 2009 & Rafael Corrrea \\
\hline Guatemala & 2008 & Alvaro Colom \\
\hline Guatemala & 2012 & Otto Pérez Molina \\
\hline Honduras & 2009 & Roberto Micheletti \\
\hline Honduras & 2010 & Porfírio Lobo \\
\hline México & 2000 & Vicente Fox \\
\hline México & 2006 & Felipe Calderón \\
\hline Nicarágua & 2007 & Daniel Ortega Saavedra \\
\hline Nicarágua & 2011 & Daniel Ortega Saavedra \\
\hline Panamá & 2004 & Martín Torrijo Espinos \\
\hline Panamá & 2009 & $\underline{\text { Ricardo Martinelli }}$ \\
\hline Paraguai & 2003 & Óscar Nicanor Duarte Frutos \\
\hline Paraguai & 2008 & Fernando Lugo \\
\hline Peru & 2006 & Alan García Perez \\
\hline Peru & 2011 & Ollanta Humala \\
\hline República Dominicana & 2004 & Leonel Fernandez \\
\hline República Dominicana & 2008 & Danilo Medina \\
\hline Uruguai & 2004 & Tabaré Vázquez \\
\hline Uruguai & 2009 & José Mujica \\
\hline Venezuela & 2006 & Hugo Chavez \\
\hline
\end{tabular}


ANEXO 2: Tabela 2 - Posicionamento dos presidentes/partido no Espectro Ideológico

\begin{tabular}{|c|c|c|c|}
\hline País & Presidente & Partido & $\begin{array}{ll}\text { Posicionamento } & \text { no } \\
\text { Espectro Ideológico } & \end{array}$ \\
\hline Argentina & $\begin{array}{l}\text { Cristina Fernández de } \\
\text { Kirchner }\end{array}$ & Partido Justicialista & Esquerda \\
\hline Argentina & $\begin{array}{l}\text { Cristina Fernández de } \\
\text { Kirchner }\end{array}$ & Partido Justicialista & Esquerda \\
\hline Bolívia & Juan Evo Morales & Movimiento al Socialismo - MAS & Esquerda \\
\hline Bolívia & Juan Evo Morales & Movimiento al Socialismo - MAS & Esquerda \\
\hline Brasil & Dilma Rousseff & Partido dos Trabalhadores & Esquerda \\
\hline Brasil & Luis Inácio Lula da Silva & Partido dos Trabalhadores & Esquerda \\
\hline Chile & Miguel Juan Piñera & Renovación Nacional - RN & Direita \\
\hline Chile & Michele Bachelet & Partido Socialista de Chile - OS & Esquerda \\
\hline Colômbia & $\begin{array}{l}\text { Juan Manuel Santos } \\
\text { Calderón }\end{array}$ & Partido Liberal Colombiano & Direita \\
\hline Colômbia & Álvaro Uribe Vélez & Primeiro Colômbia & Direita \\
\hline Costa Rica & $\begin{array}{l}\text { Laura Chinchilla } \\
\text { Miranda }\end{array}$ & Partido Liberación Nacional - PLN & Direita \\
\hline Costa Rica & Óscar Rafael Sánchez & Partido Liberación Nacional - PLN & Direita \\
\hline El Salvador & $\begin{array}{l}\text { Carlos Mauricio Funes } \\
\text { Cartagena }\end{array}$ & $\begin{array}{l}\text { Alianza Republicana Nacionalista- } \\
\text { ARENA }\end{array}$ & Direita \\
\hline El Salvador & $\begin{array}{l}\text { Elias Antonio Saca } \\
\text { González }\end{array}$ & $\begin{array}{l}\text { Alianza Republicana Nacionalista - } \\
\text { ARENA }\end{array}$ & Direita \\
\hline Equador & Rafael Corrrea & Alianza Pais (Patria Altiva y Soberana) & Esquerda \\
\hline Equador & Alfredo Palacio & Nenhum Partido & Esquerda \\
\hline Guatemala & Otto Pérez Molina & Partido Patriota - PP & Direita \\
\hline Guatemala & Alvaro Colom & Unidad Nacional de la Esperanza & Esquerda \\
\hline Honduras & Porfírio Lobo & Partido Liberal de Honduras -PLH & Direita \\
\hline Honduras & Roberto Micheletti & Partido Nacional de Honduras -PNH & Direita \\
\hline México & Felipe Calderón & Partido Acción Nacional - PAN & Direita \\
\hline México & Vicente Fox & Partido Acción Nacional - PAN & Direita \\
\hline Nicarágua & Daniel Ortega Saavedra & Frente Sandinista de Libertação Nacional & Esquerda \\
\hline Nicarágua & Daniel Ortega Saavedra & Frente Sandinista de Libertação Nacional & Esquerda \\
\hline Panamá & Ricardo Martinelli & Cambio Democrático & Esquerda \\
\hline Panamá & Martín Torrijos Espino & Partido Revolucionario Democrático - PRD & Esquerda \\
\hline Paraguai & Fernando Lugo & Partido Demócrata Cristiano & Esquerda \\
\hline Paraguai & $\begin{array}{l}\text { Óscar Nicanor Duarte } \\
\text { Frutos }\end{array}$ & Partido Colorado & Direita \\
\hline Peru & Ollanta Humala & Partido Nacionalista Peruano - PNP & Esquerda \\
\hline Peru & Alan García Perez & $\begin{array}{l}\text { Alianza Popular Revolucionaria Americana } \\
\text { - APRA }\end{array}$ & Esquerda \\
\hline $\begin{array}{l}\text { República } \\
\text { Dominicana }\end{array}$ & Danilo Medina & Partido de la Liberación Dominicana & Esquerda \\
\hline $\begin{array}{l}\text { República } \\
\text { Dominicana }\end{array}$ & Leonel Fernandez & Partido da Libertação Dominicana & Esquerda \\
\hline Uruguai & José Mujica & Frente Amplio & Esquerda \\
\hline Uruguai & Tabaré Vázquez & Frente Amplio & Esquerda \\
\hline Venezuela & Hugo Chavez & $\begin{array}{l}\text { Partido Socialista Unido de Venezuela - } \\
\text { PSUV }\end{array}$ & Esquerda \\
\hline Venezuela & Hugo Chavez & $\begin{array}{l}\text { Partido Socialista Unido de Venezuela - } \\
\text { PSUV }\end{array}$ & Esquerda \\
\hline
\end{tabular}




\section{ANEXO 3 - Construção do banco de dados (nível agregado)}

Aquelas variáveis relacionadas à avaliação subjetiva do desempenho econômico retrospectivo sociotrópico e individual foram verificadas, respectivamente, através das seguintes questões, presentes nos bancos de dados do Barômetro das Américas: O sr/sra. considera que a situação econômica atual do país está melhor, igual, ou pior que há doz̧e meses? E: O sr/sra acha que sua atual situação econômica está melhor, igual ou pior que a de há doẓe meses? Tais questões são comumente utilizadas pela literatura sobre o tema visando o mesmo tipo de mensuração objetivada por nós, conforme exposto no capítulo teórico (Weyland, 1998, 2000, 2003; Lewis-Beck e Stegmaier, 2008; Lewis-Beck e Ratto,2013; Hesli e Bashkirova, 2001; Veiga, 2013).

As alternativas de respostas eram "melhor", "igual" ou "pior". Com intuito de analisar somente o impacto da avaliação positiva da economia, selecionamos o percentual de respondentes que consideraram que a sua condição econômica, bem como a de seu país, encontrou-se, naquele momento, melhor do que há doze meses. A porcentagem de respostas positivas foi inserida no banco de dados agregados.

As variáveis relativas à avaliação subjetiva de do desempenho do presidente nas políticas públicas e grandes temas da América Latina foram avaliadas segundo as seguintes questões: 1) para avaliação da atuação do presidente no que se refere ao combate à pobreza: Até que ponto o sr./sra. diria que o governo federal atual combate a pobreza? 2) Intentando avaliar a atuação na promoção e proteção dos princípios democráticos: Até que ponto o sr./sra. diria que o governo federal atual promove e protege os princípios democráticos? 3) Referente à avaliação da atuação do presidente no combate à corrupção: Até que ponto diria que o governo federal atual combate a corrupção no governo? 4) Para avaliar a atuação do presidente sobre a segurança cidadã: Até que ponto o sr./ sra. diria que o governo federal atual melhora a segurança do cidadão?

Todo esse conjunto de questões se apresentava, originalmente, no banco de dados do Barômetro das Américas, com respostas sob forma escalar, em que os respondentes poderiam avaliar o desempenho do governo federal em uma escala de sete pontos, que variavam de um a sete, sendo que um significava nada e sete significava muito. Posto que a avaliação que nos interessa é a avaliação positiva, foram consideradas como avaliação positiva aquelas que iam de cinco a sete. Sendo assim, somou-se a porcentagem que avaliou a questão atribuindo os valores de cinco, seis, ou sete. 
Para a análise de posicionamento no espectro ideológico, baseamo-nos na seguinte questão: Nessa folba há uma escala, de 1 a 10, que vai da esquerda para a direita. Hoje em dia, quando se conversa de tendências politicas, fala-se de pessoas que simpatizam mais com a esquerda e de pessoas que simpatizam mais com a direita. De acordo com o sentido político que os termos "esquerda" e "direita" têm para o sr./sra, onde o sr./sra. se situa nesta escala? Indique o número que se aproxima mais da sua própria posição. Através dela, sopesamos a posição ideológica de cada um dos 36 presidentes latino-americanos estudados, para que fosse possível testar a variável ideologia que estivesse próxima, isto é, alinhada àquela do presidente avaliado. Isso com o intuito de analisar o quanto a ideologia em conformidade com a do presidente refletiria em sua avaliação. Visando tal verificação, desconsideramos a porcentagem de respondentes auto-posicionados na pontuação cinco (que seria equivalente ao centro) e adotamos como padrão que aqueles que se posicionaram entre um e quatro, foram convencionados como esquerda. Enquanto que aqueles que afirmaram se localizar entre seis e dez, foram considerados como direita. Assim, os presidentes mais à direita tiveram essa variável representada pela porcentagem de respondentes à direita. Da mesma forma, os presidentes mais à esquerda tiveram a variável representada pela porcentagem de respondentes à esquerda. A classificação dos presidentes em direita e esquerda pode ser vista em anexo (Tabela/anexo 2) e atendeu aos critérios de Norberto Bobbio (1995), segundo o qual a esquerda se identifica com forças políticas que agem em prol da igualdade do ponto de vista econômico, social, racial, de gênero etc.

A variável que diz respeito ao crescimento econômico é o PIB por habitante em dólares. A fonte da mesma é o CEPAL. Utilizamos como padrão o PIB relativo ao ano anterior aos bancos de dados do Barômetro das Américas que forneceram os dados de avaliações subjetivas. A escolha das datas às quais a variável de crescimento econômico iria corresponder se justifica pelo fato de estarmos mensurando a avaliação subjetiva retrospectiva, onde o marco são os doze meses anteriores.

Outra variável utilizada para mensurar dados objetivos, com o intuito de se verificar a possível contraposição à avaliação subjetiva da opinião pública é o gasto público social por habitante em dólar. Esse dado, também retirado do CEPAL, aponta quanto cada governo dos países da América Latina investiu em gasto com o setor social por habitante. Sabendo que o investimento social foi um importante componente para a redução de pobreza na América Latina, como nos apontaram Veiga (2013) e Portela Filho (1994) visamos testar se essa variável contribuiu, de alguma forma, para a avaliação do presidente. 
Por se tratar de um banco de dados pronto - esse, oferecido pelo CEPAL sobre gasto público social por habitante - existem algumas limitações que nos levaram a algumas adaptações: essa variável tinha dados coletados até o ano de 2010. Como o padrão estabelecido foi utilizar o dado relativo ao mesmo ano que os bancos de dados do Barômetro das Américas utilizados para cada país, a necessidade de dados de 2012 não foi sanada, deixando alguns dos países do banco utilizado para a análise empírica deste trabalho, sem essa informação. Isso porque, no caso de presidentes eleitos anteriormente (a despeito do banco de dados do Barômetro das Américas utilizado ser o de 2012), foram usados os dados do CEPAL de 2010. Caso esse representado pelos presidentes eleitos após o ano de 2011, que não tiveram seus dados considerados nessa variável. A esta condição, correspondem cinco casos: Argentina, Guatemala, México, Nicarágua e Peru.

Além disso, quando não foi possível contemplar o padrão estabelecido, a alternativa adotada foi utilizar o dado de gasto público social por habitante relativo ao ano anterior àquele do questionário aplicado, desde que a informação dissesse respeito ao governo do presidente latinoamericano estudado. Contudo, nem todos os países tinham esses dados disponibilizados referentes aos anos dos quais necessitávamos. Nessa situação, alguns casos não tiveram seus dados considerados nessa variável. Foram eles: Bolívia, Brasil, Honduras, e Paraguai; somando um total de nove casos que tiveram de ser considerados missing no que se refere à variável gasto público social por habitante.

Índice de percepção da corrupção é uma medida indireta que se propõe a mensurar o nível de percepção da corrupção em diversos países (Abramo, 2005). Os dados que satisfizeram essa variável foram retirados da Transparency International. Esse índice é compilado através de outros indicadores considerados a partir da opinião de pessoas ligadas a órgãos transnacionais que expressam o nível de corrupção que elas percebem existir nos países. A partir desses números, a Transparency International elabora um ranking, no qual incorpora todos os países analisados. Os números de avaliação variam de zero a cem, sendo que quanto maior for esse número, maior a transparência do sistema institucional. A escolha dessa variável se dá na intenção de verificarmos o possível contraponto existente entre a percepção da corrupção e a avaliação subjetiva da opinião pública no que se refere ao desempenho do governo federal ao combate da mesma, além de, sobretudo, constatar o possível impacto desse na avaliação positiva do presidente; ainda que se reconheça as limitações e subjetividades de tal índice, provenientes da dificuldade de análise empírica da corrupção, medida que é, necessariamente, ilícita e, portanto, 
secreta, o que a leva à grande dificuldade de verificação (idem). Foram selecionados os dados referentes ao mesmo ano do Banco de dados do Barômetro das Américas utilizado para cada um dos presidentes estudados. 